\title{
Education, reading, and familial tendency as risk factors for myopia in Hong Kong fishermen
}

\author{
L Wong, D Coggon, M Cruddas, C H Hwang
}

\begin{abstract}
Study objective-The aim was to assess the influence of childhood reading on the development of myopia after allowance for familial differences in susceptibility.

Design-The study was a cross sectional survey.

Setting-Four fishing harbours in Hong Kong in 1989.

Subjects-Participants were 408 men and women aged 15-39 years old from 159 families.
\end{abstract}

Main results-Histories of school attendance and reading habits in childhood were obtained at interview. Myopia was assessed by retinoscopy. Associations between myopia (defined as a refractive error of at least $-1.0 \mathrm{D}$ in one or both eyes) and indices of reading in childhood were explored. Myopia was more common in subjects who had attended school (odds ratio $=1 \cdot 7,95 \%$ CI $1 \cdot 0-3 \cdot 0$ ), with the highest risks in those who had started school at the earliest ages and who had spent the most time reading and writing while at primary school. Allowance for familial tendency to myopia produced no diminution in the risks associated with reading.

Conclusions-These data support the hypothesis that reading in childhood is a cause of short sight.

f Epidemiol Community Health 1993; 47: 50-53

Myopia is a common cause of visual impairment in industrialised countries. Twin studies indicate a genetic component in its aetiology, ${ }^{1-3}$ but the disorder must also have powerful environmental determinants. Only environmental influences could explain the dramatic increase in prevalence which has been observed over a single generation in North American Eskimo and Indian communities as they have changed to a more western way of life. ${ }^{4-8}$ Various explanations have been proposed for this rise in prevalence, including the advent of electric lighting and television, but the most plausible theory links the development of myopia with the introduction of formal education, and in particular with reading in childhood.

The idea that close visual work might cause or promote myopia has been mooted for many years. It is supported by the well documented association between short sight and educational attainment. $^{9-16}$ This relation appears not to be explained by a tendency for myopic individuals to take up academic pursuits as a consequence of their disability, since in longitudinal studies differences in academic performance have been demonstrated even before the onset of myopia. ${ }^{17-19}$ However, some investigators have suggested that the association occurs because intelligence is genetically linked to short sight. ${ }^{20-22}$

Formal education only became compulsory in Hong Kong in 1979. A recent survey of the local fishing community, most of whom still live and work on their boats in close family groups, showed that only half of the young adults had been to school. ${ }^{23}$ We have exploited this unusual circumstance to examine the influence of childhood reading on myopia while allowing for possible familial differences in susceptibility.

\section{Methods}

Data collection was carried out during the Chinese New Year festival when the fishing fleets gather in harbour for the holiday period. Four harbours were visited, and in each harbour the survey team was introduced to a few families by an official of the local fishing association. Adjacent boats were then approached in turn, each family providing an introduction to the next. Virtually all of the families approached agreed to take part in the study.

When a household agreed to participate, a family tree was constructed and all available persons aged 15-39 years were interviewed. A structured questionnaire was administered by a single interviewer (LW) to obtain demographic details, any history of using spectacles, and information about possible risk factors for myopia. In particular, we asked whether subjects had attended school, and if so, from what age and for how long; how many hours per day they spent reading and writing before age 12 years; and whether they had read a paper, magazine, or book in the past week. The last question was included as an indirect index of reading in childhood that might be answered more reliably than questions about reading many years in the past.

Ophthalmic examinations were carried out by a qualified ophthalmologist (CHW) at the same visit, but without knowledge of the interview findings. Both eyes were examined by retinoscopy with relaxation of accommodation by a fogging lens, and refractive errors were converted to spherical equivalents by adding half the cylindrical error to the spherical error. Myopia was defined a priori as a refractive error of at least $-1.0 \mathrm{D}$ in one or both eyes. Severity of myopia was classified according to the mean refractive error for both eyes.

Where family members aged 15-39 years were unavailable for interview and examination, more limited information was sought by proxy from their relatives. We asked whether they used spectacles, and if so, what for; and whether they had been to school. 
Environmental risk factors for myopia were examined by logistic regression with allowance for age (in five year strata) and sex. The potential influence of genetic predisposition was explored by first deriving each subject's fitted probability of myopia from a logistic regression model incorporating age, sex, and key environmental risk factors. A subject's familial tendency to myopia was then scored by comparing the number of cases of myopia among his first degree relatives in the study sample with that expected from their fitted probabilities of the disorder. Tendencies were ranked according to the probability of obtaining a deficit or excess of myopia in first degree relatives as extreme as that observed, and were grouped in quintiles. This grouped measure of familial tendency was then entered into the logistic regression model along with the environmental risk factors.

\section{Results}

One hundred and fifty nine families took part in the study, and these included 1018 persons aged 15-39 years. Four hundred and eight subjects (277 men and 131 women) were interviewed in

Table I Associations of myopia with indices of reading. The analysis included all subjects who were interviewed and examined. Each risk factor was examined independently with adjustment for age (in five strata) and sex.

\begin{tabular}{|c|c|c|c|}
\hline \multirow[b]{2}{*}{ Risk factor } & \multicolumn{2}{|c|}{ Number of subjects } & \multirow{2}{*}{$\begin{array}{l}\text { Odds ratio (with } 95 \% \\
\text { confidence interval) }\end{array}$} \\
\hline & Myopic & Not myopic & \\
\hline $\begin{array}{l}\text { Attended school } \\
\text { No } \\
\text { Yes }\end{array}$ & $\begin{array}{l}28 \\
67\end{array}$ & $\begin{array}{l}124 \\
187\end{array}$ & $\stackrel{1}{1 \cdot 7(1 \cdot 0-3 \cdot 0)}$ \\
\hline $\begin{array}{l}\text { Years of school atte } \\
\text { Never at school } \\
1-3 \\
4-6 \\
7-10\end{array}$ & $\begin{array}{l}28 \\
25 \\
28 \\
14\end{array}$ & $\begin{array}{r}124 \\
63 \\
87 \\
37\end{array}$ & $\begin{array}{l}1 \\
1.9(1.0-3.6) \\
1.5(0.8-2.9) \\
1.8(0.8-4.0)\end{array}$ \\
\hline $\begin{array}{l}\text { Age started at schoo } \\
\text { Never at school } \\
10-16 \\
8-9 \\
7 \\
4-6\end{array}$ & $\begin{array}{l}28 \\
16 \\
15 \\
17 \\
19\end{array}$ & $\begin{array}{r}124 \\
43 \\
56 \\
47 \\
41\end{array}$ & $\begin{array}{l}1 \\
1 \cdot 8(0 \cdot 9-3 \cdot 7) \\
1 \cdot 3(0 \cdot 6-2 \cdot 7) \\
1 \cdot 7(0 \cdot 8-3 \cdot 7) \\
2 \cdot 3(1 \cdot 1-4 \cdot 9)\end{array}$ \\
\hline $\begin{array}{l}\text { Hours/d reading an } \\
0 \\
1 \\
2 \\
3+\end{array}$ & $\begin{array}{l}39 \\
18 \\
24 \\
14\end{array}$ & $\begin{array}{r}151 \\
72 \\
55 \\
33\end{array}$ & $\begin{array}{l}1 \\
1.0(0.5-1.9) \\
1.7(0.9-3.3) \\
1.7(0.8-3.6)\end{array}$ \\
\hline $\begin{array}{l}\text { Read a paper, maga } \\
\text { No } \\
\text { Yes }\end{array}$ & $\begin{array}{l}53 \\
42\end{array}$ & $\begin{array}{l}201 \\
110\end{array}$ & $\begin{array}{l}1 \\
1.5(0.9-2.4)\end{array}$ \\
\hline
\end{tabular}

Table II Associations of myopia with television viewing and sleeping habits in childhood. The analysis included all subjects who were interviewed and examined. Each risk factor was examined independently with adjustment for age (in five strata) and sex.

\begin{tabular}{|c|c|c|c|}
\hline \multirow[b]{2}{*}{ Risk factor } & \multicolumn{2}{|c|}{ Number of subjects } & \multirow{2}{*}{$\begin{array}{l}\text { Odds ratio (with } 95 \% \\
\text { confidence interval) }\end{array}$} \\
\hline & Myopic & Not myopic & \\
\hline $\begin{array}{l}\text { Had television before age } 12 \\
\text { No } \\
\text { Yes }\end{array}$ & $\begin{array}{l}36 \\
59\end{array}$ & $\begin{array}{l}141 \\
170\end{array}$ & $1.7(0.9-3.4)$ \\
\hline $\begin{array}{l}\text { Years with television before age } 12 \\
0 \\
1-3 \\
4-6 \\
7-12\end{array}$ & $\begin{array}{l}36 \\
26 \\
14 \\
19\end{array}$ & $\begin{array}{r}141 \\
45 \\
65 \\
60\end{array}$ & $\begin{array}{l}1 \\
2 \cdot 5(1 \cdot 2-5 \cdot 1) \\
0 \cdot 9(0 \cdot 4-2 \cdot 2) \\
1 \cdot 3(0 \cdot 5-3 \cdot 3)\end{array}$ \\
\hline $\begin{array}{l}\text { Hours/d watching television before age } 12 \\
\text { Never had television } \\
1-2 \\
3-4 \\
5+\end{array}$ & $\begin{array}{l}36 \\
21 \\
24 \\
14\end{array}$ & $\begin{array}{r}141 \\
60 \\
76 \\
34\end{array}$ & $\begin{array}{l}1 \\
1 \cdot 7(0 \cdot 8-3 \cdot 7) \\
1 \cdot 7(0 \cdot 8-3 \cdot 6) \\
2 \cdot 1(0 \cdot 8-5 \cdot 4)\end{array}$ \\
\hline $\begin{array}{l}\text { Slept in daylight or with light on } \\
\text { during childhood } \\
\text { No } \\
\text { Yes }\end{array}$ & $\begin{array}{l}77 \\
18\end{array}$ & $\begin{array}{r}255 \\
53\end{array}$ & $\begin{array}{l}1 \\
1 \cdot 1(0 \cdot 6-2 \cdot 1)\end{array}$ \\
\hline
\end{tabular}

person and examined, while more limited information was obtained by proxy for the remaining 610 .

Among the 408 subjects who were at home when the survey team visited, refractive errors varied from $-8.0 \mathrm{D}$ to $+3.5 \mathrm{D}$ with mean $-0.55 \mathrm{D}$ and standard deviation $1 \cdot 18 \mathrm{D}$. Ninety five $(23 \%)$ were myopic according to the criteria which had been specified before the analysis began.

Table I summarises the relation of myopia to various indices of reading in the subjects who were interviewed and examined. After allowance for age and sex, myopia was associated both with school attendance $(\mathrm{OR}=1 \cdot 7,95 \%$ CI $1 \cdot 0-3 \cdot 0)$ and with having read a paper, magazine, or book in the past week $(\mathrm{OR}=1 \cdot 5,95 \%$ CI $0 \cdot 9-2 \cdot 4)$. There was no clear dose-response effect in relation to the number of years spent at school, but the risk of myopia tended to be greatest in those who had started school at the youngest age, and who had spent the most time per day reading and writing before the age of 12 . We found no evidence that this effect depended on the type of light (natural or artificial) used for reading.

Table II shows the relation of myopia to television viewing and sleeping habits in childhood. Myopia was more common in subjects who had had a television before they were 12 ( $\mathrm{OR}=1 \cdot 7,95 \%$ CI 0.9-3.4), and risk increased with the time per day spent watching television, although not with duration of television ownership in childhood. Sleeping in a lighted room during childhood showed no relation to myopia.

Table III shows the association of television viewing and indices of reading with severity of myopia. For each risk factor, odds ratios were highest for the largest refractive errors.

In exploring the potential confounding effect of genetic predisposition on associations with environmental risk factors, we used the variables "hours/day reading and writing before age 12" and "hours/day watching television before age 12 " together with age and sex to derive fitted probabilities of myopia and thence familial tendency scores. Data on at least one first degree relative were available for 298 subjects. Table IV summarises the findings when familial tendency and environmental risk factors were examined simultaneously in a logistic model. Risk of myopia was increased in subjects with a familial tendency to the disorder, and particularly in the highest quintile of the familial tendency distribution $(\mathrm{OR}=5 \cdot 1,95 \%$ CI $2 \cdot 0-12 \cdot 7)$. However, familial predisposition did not explain the environmental associations. In particular, the risks associated with reading were if anything exaggerated when familial tendency and television viewing were taken into account. A similar exaggeration was observed if age at starting school was used as the measure of close visual activity rather than reported time spent reading.

To check for possible bias from the unavailability of some family members, we analysed the information on use of spectacles and school attendance that was obtained for all 1018 subjects, whether or not they were present when the survey team visited. Six hundred and seventeen subjects $(61 \%)$ had been to school, and $164(16 \%)$ wore spectacles for short sight. After allowance for age and sex, use of spectacles for short sight was 
Table III Severity of myopia in relation to reading and television. The analysis included all subjects who were interviewed and examined. Each risk factor was examined independently with allowance for age (in five strata) and sex. Severity of myopia was classified according to the mean refractive error for both eyes.

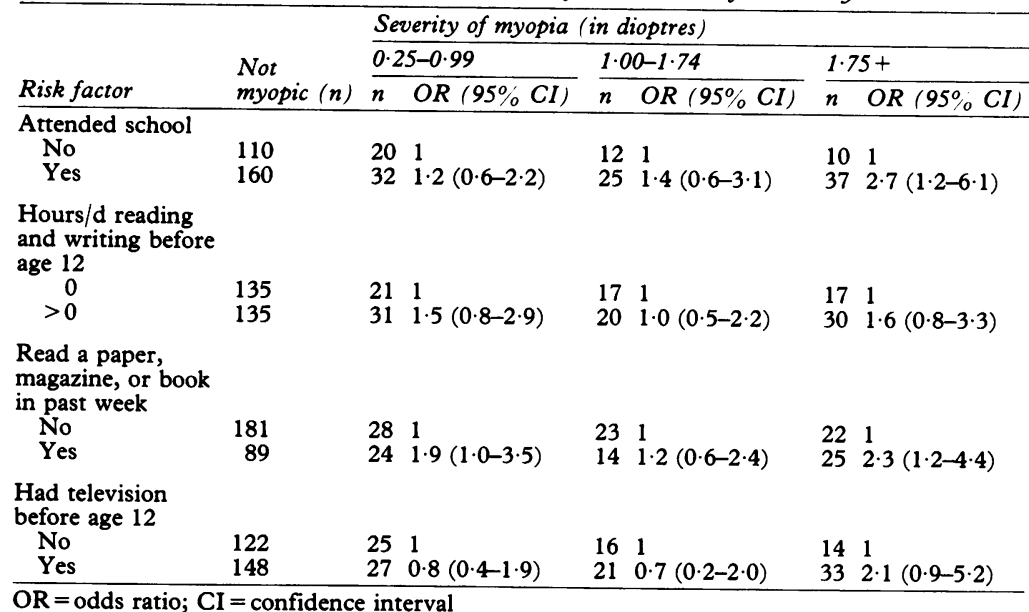

strongly associated with school attendance $(\mathrm{OR}=12 \cdot 4,95 \%$ CI $6 \cdot 3-24 \cdot 2)$. The association for those not interviewed $(\mathrm{OR}=11.4)$ was of a similar order to that in those available for examination $(\mathrm{OR}=16 \cdot 9)$. These much higher odds ratios than in the analyses based on measured refraction reflected a tendency for school attenders to obtain spectacles more frequently at a given level of refractive error. The potential confounding effect of familial tendency was examined for the 1018 subjects as in the main analysis, but with use of spectacles for short sight as the outcome variable, and fitted probabilities based on age, sex, and school attendance. Risk of spectacle use increased steeply with familial tendency, but after adjustment for this, the association with having been to school was virtually unchanged. $(\mathrm{OR}=12 \cdot 9,95 \%$ CI $6 \cdot 5-25 \cdot 8)$

\section{Discussion}

Our findings indicate that the association between myopia and educational attainment is not

Table IV Associations of myopia with reading, television viewing, and familial tendency. The analysis included all subjects who were interviewed and examined and for whom at least one first degree relative was interviewed and examined. All risk factors were examined simultaneously in a single logistic regression model.

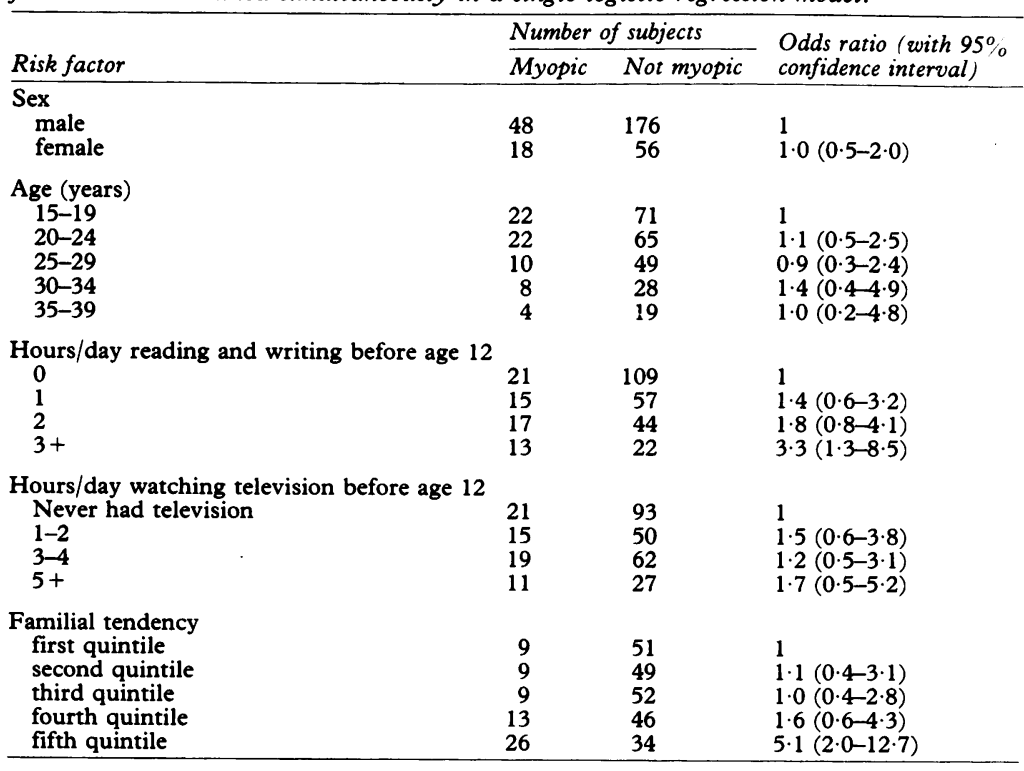

explained by a confounding effect of familial tendency to the disorder. This suggests that it is not a consequence of genetic linkage with intelligence. An adverse effect of reading in childhood seems a more likely explanation.

During the Chinese New Year festival virtually all fishing boats return to harbour. Thus our sampling frame is likely to have been representative. Unfortunately, we were not able to examine all selected family members in our target age range. Some, particularly women who had married, were living elsewhere, and others were not at home when the survey team visited. However, we were able to obtain information about use of spectacles among these missing subjects. Interpretation is complicated by the observed tendency for school attenders to obtain glasses more often than non-attenders at a given level of myopia. Nevertheless, the persistence of the association between school attendance and use of spectacles for myopia, after allowance for familial tendency, suggests that the parallel finding in the subset of subjects who underwent examination was not simply a product of selection bias.

Ideally, refraction would have been assessed after cycloplegia, but we were concerned that use of mydriatics might substantially reduce response rates. Any errors from the use of a fogging lens rather than cycloplegia should be nondifferential, and thus would tend to obscure rather than exaggerate associations.

There is no generally accepted definition of myopia in epidemiological studies, and the criterion which we adopted in our main analysis was to some extent arbitrary. It was chosen, however, before the analysis was carried out. Furthermore, when severity of myopia was examined, associations were strongest for the largest refractive errors (table III). This suggests that the definition of myopia was not a critical determinant of our findings.

Our questionnaire included several indices of reading in childhood, all of which were associated with myopia. Proxy measures such as educational history were used in addition to a direct report of time spent reading before age 12 (ie, while at primary school), because they were likely to be recalled more reliably. When allowance was made for familial tendency, the relation of reading to myopia was if anything strengthened. We conclude that genetic susceptibility is unlikely to be an important confounding variable.

Other investigators have also linked myopia with reading, ${ }^{11} 14$ and in one study an association with nearwork (including reading) persisted after allowance for education. ${ }^{24} \mathrm{~A}$ role for close visual activity in the aetiology of short sight is supported by the observation that monkeys become myopic when reared in hooded restraining chairs to prevent distant vision. ${ }^{25} 26$ It has been proposed that accommodation raises intraocular pressure and that this leads to myopia through elongation of the eyeball. ${ }^{27}$ But local retinal mechanisms might also be important. Chicks raised with either the nasal or temporal half of their visual field impaired by a white translucent occluder develop myopia selectively in the deprived part of the retina, ${ }^{28}$ and this has prompted the theory that myopia results from a failure of non-foveal retinal neurones to resolve the letters on a printed page because of their large receptive fields. 
Other possible environmental risk factors which we examined included sleeping in the light and watching television. It has been suggested that sleeping in the light could induce myopia through the production of unpatterned visual images on the retina. ${ }^{29}$ However we found no evidence to support this idea. We did find an association with watching television during childhood and also an increase in risk with time spent viewing. However, the association was only of borderline statistical significance and there was no dose-response effect in relation to duration of television ownership. Futher evidence is needed before this finding can be properly evaluated.

After allowance for environmental variables, we still found an association between myopia and familial tendency. A similar observation has been reported from a survey in Newfoundland where correlations between the refraction of relatives were reduced but still present after adjustment for nearwork and education. ${ }^{30}$ Our measure of familial tendency may have been influenced by residual similarities in the environment of first degree relatives after reading and television viewing had been taken into account, but it should also reflect genetic predisposition to myopia as evidenced by twin studies. ${ }^{1-3}$

The relation of myopia to reading has potential implications for treatment. In particular, if accommodation is important in the pathogenesis of short sight, then progression of myopia migh be arrested or slowed in some children by prescription of bifocal or multifocal lenses. A nonrandomised trial has suggested that bifocal lenses might be of some benefit. ${ }^{31}$ Perhaps it is time to evaluate this therapy more rigorously.

We thank Professor Newton Morton for his advice on analytical methods. LW was supported by a grant from the Croucher Foundation.

1 Sorsby A, Fraser GR. Statistical note on the components of ocular refraction in twins. F Med Genet 1964; 1: 47-9.

Danning H. Twin study on myopia. Chinese Med $1981 ; 94$ 51-5.

3 Knoblock WH, Leavenworth NM, Bouchard TJ, Eckert

ED. Eye findings in twins reared apart. Ophthalmol Paediatr Genet 1985; 5: 59-66.
4 Young FA, Leary GA, Baldwin WR, et al. The transmission of refractive errors within eskimo families. Am f Optometr Arch Am Acad Optometr 1969; 46: 676-85.

5 Morgan RW, Munro M. Refractive problems in northern natives. Can 7 Ophthalmol 1973; 8: 226-8.

6 Morgan RW, Speakman JS, Grimshaw SE. Inuit myopia: an environmentally-induced epidemic? Can Med Assoc F 1975; 112: $575-7$.

7 Woodruff ME, Samek MJ. A study of the prevalence of spherical equivalent refractive states and anisometropia in Amerind populations in Ontario. Can $\mathcal{F}$ Public Health 1977; Amerind pop

8 Johnson GJ, Matthews A, Perkins ES. Survey of ophthalmic conditions in a Labrador community I: Refractive errors. Conditions in a Labrador commun.

9 Goldschmidt E. On the aetiology of myopia. An epidemiologic study. Acta Ophthalmol 1968; 98 (suppl): 1-172.

10 Angle J. Wissmann DA. Age, reading and myopia. $A m \mathcal{F}$ Optometr Physiol Optics 1978; 55: 302-8.

11 Angle J. Wissmann DA. The epidemiology of myopia. $A m \mathfrak{F}$ Epidemiol 1980; 111: 220-8.

12 Sperduto RD, Seigel D, Roberts J, Rowland M. Prevalence of myopia in the United States. Arch Ophthalmol 1983; 101 : 405-7.

13 Ashton GC. Nearwork, school achievement and myopia. $\mathfrak{f}$ Biosoc Sci 1985; 17: 223-33.

14 Parssinen TO. Relation between refraction, education occupation and age among 26 and 46 year old Finns. $A m \mathcal{F}$ Optometr Physiol Optics 1987; 64: 136-43.

15 Rosner M, Belkin M. Intelligence, education and myopia in males. Arch Ophthalmol 1987; 105: 1508-11.

16 Teasdale TW, Fuchs J, Goldschmidt E. Degree of myopia in relation to intelligence and educational level. Lancet 1988; ii: $1351-4$

17 Douglas JWB, Ross JM, Simpson HR. The ability and attainment of short-sighted pupils. $\mathcal{F} R$ Stat Soc $A 1967$; 130: 479-503.

18 Karlsson JL. Influence of the myopia gene on brain development. Clin Genet 1975; 8: 314-8.

19 Peckham CS, Gardiner PA, Goldstein H. Acquired myopia in 11-year-old children. BMF 1977; 1: 542-5.

20 Karlsson JL. Genetics of myopia and associated mental traits. Hereditas 1986; 105: 205-8.

21 Letocha CC. Myopia. Arch Ophthalmol 1983; 101: 1301.

22 Sofaer JA, Emery AEH. Genes for super-intelligence. $\mathcal{F ~ M e d}$ Genet 1981; 18: 410-3.

23 Wong L, Coggon D. A survey of lifestyle and health in the Hong Kong fishing community. I Hong Kong Soc Community Med (in press).

24 Richler A, Bear JC. Refraction, nearwork and education. Acta Ophthalmol 1980; 58: 468-78.

25 Young FA. The effects of restricted visual space on the primate eye. Am f Ophthalmol 1961; 52: 799-806.

26 Young FA. The effect of restricted visual space on the refractive error of the young monkey eye. Invest Ophthalmol 1963; 2: 571-7.

27 Young FA. The nature and control of myopia. $f \mathrm{Am}$ Optometr Assoc 1977; 48: 451-7.

28 Wallman J, Gottlieb MD, Rajaram V, Fugate-Wentzek LA Local retinal regions control local eye growth and myopia. Local retinal regions cont

29 Anonymous. What makes some children short-sighted? Lancet 1987; ii: 1001-2.

30 Bear JC, Richler A, Burke G. Nearwork and familial resemblances in ocular refraction: A population study in resemblances in ocular refraction: A population

31 Oakley KH, Young FA. Bifocal control of myopia. Am $\mathcal{F}$ Optometr Physiol Optics 1975; 52: 758-64. 